\title{
Using the WorldCat API to Develop Data-Driven Decision-Making for Gifts-in-Kind
}

\section{Juleah Swanson and Philip B. White}

In practice, evaluation and acceptance of books donated to a library (gifts-inkind) often lack the same data-driven decision-making that libraries apply to purchased materials. Factors of "specialness" or "uniqueness" that are important components of why libraries still seek donations are not necessarily data-driven. This practice may be especially true for items located within a library's general collection, rather than special collections or archives. The research presented here develops new methods that support data-driven decision-making in evaluating gifts-in-kind, particularly for items for the general collection. The authors focus on the concept of rarity and geographic scarcity using OCLC holdings, the WorldCat API, and geospatial methods. They retroactively examined monographs added to the general collection as gifts over a ten-year period at the University of Colorado Boulder (UCB) that are an initial dataset of sixteen thousand or more books. The majority of items are neither unique or rare in holdings, nor are they geographically scarce. However, some are, and the shared characteristics of many of these rare or geographically scarce items may be relevant to Area Studies faculty, students, and researchers. While the results of this study are localized in scope, the methods developed could be easily replicated by libraries seeking to evaluate uniqueness and proximity of current or future gifts-in-kind with high efficiency and objectivity.

Juleah Swanson (juleah.swanson@colo rado.edu) is Head, Acquisition Services at the University of Colorado Boulder. Philip B. White (philip.white@colorado .edu) is the Earth Sciences and Environment Librarian at the University of Colorado Boulder.

Manuscript submitted October 5, 2018; returned to authors for revision January 30, 2019; revised manuscript submitted February 25, 2019; accepted for publication April 14, 2019.
$\mathrm{D}$ onations, also referred to as gifts-in-kind, have long been an acquisition source used to build and enhance library collections. Though donors give books and materials to libraries without monetary exchange, libraries recognize that gifts are not "free." In the current context of data and patron-driven collection development and acquisitions strategies, shortages of physical spaces, and increases in digital collections of materials and e-books, are gifts-in-kind an antiquated means of collection development and acquisition?

Anecdotal reports of donors with exquisite collections continue to circulate as library lore. A donation from a local chess enthusiast or a gift of five thousandplus volumes of British literature including rare items from notable authors such as Virginia Woolf, D.H. Lawrence, and T.S. Eliot may appear. ${ }^{2}$ Perhaps the appeal of continuing to pursue gifts-in-kind is the prospect of obtaining something truly special, items that could not otherwise be acquired on the open market. Librarians who have worked with gifts-in-kind understand that acquiring items through donation is often a matter of sifting through "trash" versus "treasure." One must determine which books, if any, will bring meaning and value to patrons, researchers, and the community. 
The University of Colorado Boulder Libraries' gift policy states that donations of interest "are often unique, rare or special collections and may include books, maps, media, archives/personal papers, artifacts, digital content and other scholarly material."2 Columbia University Libraries "welcomes gifts of materials that will significantly advance the scholarly, research, and teaching mission of the University." The Hesburgh Libraries at the University of Notre Dame acknowledges that although "materials may have value to the donor or potential value to the university, not every collection is a good fit for the Libraries." ${ }^{36}$ These examples from academic library gift policies reflect the ongoing tension between a desire to obtain materials of unique, rare, or significant value to libraries versus the often burdensome task of determining whether a potential gift meets that criteria.

This study stems from these questions and challenges faced by librarians when considering donations. How can the task of determining what is unique, rare, or of significant value from a potential donation become less burdensome for evaluators? This research explores whether new methods are available that could support the creation of more data-driven decision making in evaluating gifts-inkind, particularly for items for the general collection, rather than Special Collections or Archives. The authors focused on the concept of rarity and geographic scarcity using WorldCat holdings, the WorldCat Application Programming Interface (API), and geospatial methods. Additionally, they chose to retroactively examine a large dataset of over sixteen thousand books acquired as gifts-in-kind, to determine whether the additional data on rarity and geographic scarcity can further highlight characteristics that may suggest an item's status as "treasure."

\section{Literature Review}

The decision to continue gift-in-kind donation programs and if the effort, labor, and material cost is worth adding "free" items to a collection is a topic of debate in the professional literature. The Colorado State University Libraries disbanded their gift-in-kind donation program for all materials except special collections and archives materials. ${ }^{7}$ The authors of a study of the Colorado State program, argued that, "in this environment, adding general gift books to a physical collection must be seen at best as a secondary or tertiary collecting strategy given limited resources, limited space, and the growing demand for access to electronic content." Researchers who authored another study of New York State public, academic, and special libraries found that the majority of libraries surveyed still felt that gift-in-kind donations are valuable in serving the library's mission and community. ${ }^{9}$ At the University of Florida, a re-examination of collection development and acquisition policies and practices led to limiting just-in-case collection development to the library's preeminent collections, such as the University of Florida's Latin America and Florida History collections. ${ }^{10}$ The tightening of gifts policies by emphasizing gifts for their preeminent collections led to a reduction of donations reviewed by half and a greater percentage of acceptance. After assessing its program, librarians at the University of Saskatchewan changed their program by de-emphasizing gifts-in-kind functions and providing more explicit guidelines while still remaining "delighted to receive unique treasures that fall within its collecting parameters."

The literature on gift-in-kind donations has long addressed this tension between evaluating donations of questionable value versus finding gems among those materials. According to O'Hare and Smith,

Academic research libraries are always looking for potential collection enhancing treasures, and gifts-in-kind can be the source for those unique items which distinguish collections. The reality, however, is that the average gift-inkind is often just average and, more often, not required. ${ }^{12}$

O'Hare and Smith outline types of unwanted donations, drilling down to specific titles, that plague libraries including donations of National Geographic Magazine, Reader's Digest, and donations that literally and figuratively "smell bad" due to poor condition, the presence of mold, or have questionable provenance. ${ }^{13}$ As an evaluator of donations, Burgett affectionately ruminates on finding forgotten masterpieces for today's scholars among donated books, "which of these unrecognized titles ... will one day assume a pivotal position at the center of a new circle of thinking?"14

Differences in perceived value of materials between donors and librarians exacerbate the challenge of reviewing gifts for valuable items. In a special issue of Acquisitions Librarian on gifts-in-kind, Denning aptly writes, "wellmeaning donors, thinking every book is valuable to any library, often fail to realize how marginal their gifts may be; while others simply wish to unload unwanted books and perhaps take a tax deduction." ${ }^{, 5}$ The University of Saskatchewan Library found that gift-in-kind donations were not leading to monetary gifts as was once assumed, but instead to more gifts-in-kind of minimal value to the library. ${ }^{16}$ Similarly, East Carolina University Libraries compared the donor records for both gift-in-kind and monetary donations, and though records were incomplete, they found minimal overlap between the two groups of donors, suggesting that gift-in-kind donors and monetary donors are separate groups of people. ${ }^{17}$

\section{Automated Tools for Evaluation}

To minimize the impact of gifts-in-kind on resources, librarians have sought automated tools for evaluating and 
processing donations. In 1999, Johnson reviewed tools and processes, utilizing online catalogs, databases, and integrated library systems that allowed for electronic record keeping, plus the advent of email to communicate about gifts and exchanges as advantageous advances in how libraries could better manage gift-in-kind processes and donations. That paper does not address tools or automation for the upfront evaluation of potential gift-in-kind donations. ${ }^{18}$ The Getting It System Toolkit (GIST) Gift and Deselection Manager (GDM), developed at the State University of New York Geneseo, was an open-source software application developed to optimize workflows specifically for evaluating gifts-inkind and address workflows for deselection, weeding, and withdrawal. ${ }^{19}$ It automates and gathers data from a number of sources using third-party APIs, is interoperable with OCLC Connexion, and provides the ability to automate the creation of donation thank you letters. Unfortunately, a May 29, 2018 message on the GIST website indicated that there was a discontinuation of support for all GIST applications, including a beta version of GMD Online. ${ }^{20}$

The concept behind GIST's GDM was to provide users with data to evaluate donated items against an institution's collection and other libraries' collections. This utility speaks to the type of intra-library collection analysis librarians often seek to perform. Some researchers have turned to OCLC's WorldCat database to answer these types of collection comparison questions. In a 2006 paper, Brewer described using WorldCat's advanced search function to conduct collection comparison of Russian language materials between two libraries. ${ }^{21}$ Genone and Wright described how OCLC's WorldCat Collection Analysis software aided in conducting a collection comparison among research libraries in Australia to better understand the extent of duplication across Australian libraries. ${ }^{22}$

\section{Holdings Analysis}

Although no definitive threshold of OCLC holdings exists that determines an item's rarity, a number of projects and publications have sought to use holdings counts to provide context for rarity and specialness. In the 2016 ACRL Guidelines on the Selection and Transfer of Materials from General Collections to Special Collections, a series of examples help illustrate definitions of rarity and scarcity. One example includes "fewer than ten copies held in the United States." ${ }^{\prime 23}$ At Eastern Michigan University Library, researchers analyzed the general collection to determine whether items should be transferred from the browsing collection to the library's off-site storage facility or to Archives and Special Collections. ${ }^{24} \mathrm{~A}$ holdings analysis of fewer than ten OCLC holdings worldwide, or fewer than three OCLC holdings at Michigan institutions, plus other criteria, determined if items should be moved out of the general collection. In an analysis of Russian language materials at Indiana University and the University of Arizona, a study compared the number of items unique to these institutions, followed by the number of items held by four or fewer other institutions, and then items shared by five to twenty-four, twenty-five to forty-nine, fifty to one hundred, one hundred to five hundred and more than five hundred libraries. ${ }^{25}$ The author used this analysis to gauge not only what were unique and more scarce items, but also what were the more prevalent and common items held in these collections. As previous analyses and guidelines have demonstrated, ten or less holdings worldwide may be a useful benchmark.

\section{Methodology}

\section{Gift-in-Kind Item Data}

This research examines monographs added to the general collection, meaning items available for circulation, during a ten-year period from 2006 to 2016 and acquired as giftsin-kind. This also includes circulating items houses at offsite storage. All other formats are excluded from analysis, including music scores, serials, and maps; items housed in special collections, archives, or other non-general collection locations; and items with status codes for limited use, withdrawals, or other codes indicating unavailability.

Item records were identified through the following criteria: created between January 1, 2006, to December 31, 2016; uses the bibliographic code for format type as monograph; and contains the local item note used to identify items added to the collection via gift-in-kind donations. The initial set of items was generated through a query of records from CU Boulder Libraries' integrated library system, Innovative Interfaces' Sierra, generating a list of 17,934 items. Within this initial set of data, duplicate OCLC numbers were found, and the data was deduplicated down to 16,481 records.

\section{OCLC Holdings Data}

The WorldCat Search API was used to examine the location and number of holdings for each item in the data set. OCLC maintains over twenty APIs for library use. ${ }^{26}$ The APIs are available to all OCLC contributing libraries with holdings in WorldCat. ${ }^{27}$ The WorldCat Search API provides bibliographic and location information for items in the WorldCat database. It is a Representational State Transfer (REST) API, whereby REST is a set of principles used in the design of web services. ${ }^{28}$ The WorldCat Search API is queried by constructing a URL containing the search parameters and the API's base URL. ${ }^{29}$ REST is a protocol and method for data exchange on the web, and these types of APIs are 
easily queried by entering a query in a web browser. To determine the location of a particular item by its OCLC number in WorldCat, the "GetByOCLCNumber" method was used for this study. OCLC offers two levels of access to its APIs: Sandbox and Production. Users must request an API key from OCLC to use its APIs at either level. API keys are a common method of authentication for REST APIs. Because the Sandbox key is limited to a hundred requests per day, a production key was obtained. Users can obtain a production key by submitting a request with project justification. ${ }^{30} \mathrm{~A}$ location query using the "GetByOCLCNumber" method requires an OCLC number, library's zip code, and API key. An example query would appear as:

http://www.worldcat.org/webservices/catalog/content/libraries $/$ OCLC-NUMBER $\}$ ?location $=\{$ ZIPCODE $\} \&$ maximumLibraries $=50 \&$ wskey $=\{\mathrm{A}$ PI-KEY\}.

This type of query shows the fifty nearest libraries holding the particular item and each library's city, state, and zip code. The WorldCat Search API returns response data in XML format. If the item queried is owned by a local library (in this case, CU Boulder Libraries), it is the first result. For the purpose of this research, identifying each holding location for every item was unnecessary and unwieldy. However, limiting to ten holdings locations did not present sufficient information. The authors obtained the first fifty nearest holdings locations, with the intent of analyzing items with holdings at one to forty-nine institutions, and the location of the nearest copy for all items. An alternative to the "GetByOCLCNumber" method is the "GetByISBN" method, which returns the same results. The "GetByISBN" method may be useful in cases when books are unprocessed and not yet cataloged, such as with donations that are still under consideration.

The benefit of obtaining location data via the WorldCat Search API is the ability to automate the data gathering process. A Python script was developed to interact with the API. Beginning with the list of 16,481 OCLC numbers, the script inserted each number into a query formatted as a URL, iteratively queried the WorldCat Search API, and parsed each XML response into a comma separated value (CSV) file. This process was fully automated. Use of OCLC's APIs must comply with the WorldShare Platform Terms and Conditions. ${ }^{31}$ The resulting CSV contained up to the fifty libraries nearest to the CU Boulder Libraries zip code (80309) for each OCLC number that was queried. ${ }^{32}$

\section{Geospatial Methods}

Since distance from the queried zip code is not included in response data from the WorldCat Search API, these measures were calculated using geospatial techniques. Each unique library in the response data was compiled into a new CSV file. The CSV file contained the zip code-level address information for each library in the dataset. ${ }^{33}$ The MapQuest Geocoding API was then used to assign latitude and longitude coordinates to each library. ${ }^{34}$ Geocoding is a geospatial operation that assigns latitude and longitude coordinates based on street addresses. ${ }^{35}$ The geocoding process was automated in a similar process to the API methods described above. The MapQuest Geocoding API returns data in JavaScript Object Notation (JSON) format, and the response coordinate data for each library were parsed into a CSV file. Depending on the accuracy of the address database queried, a small amount of error is expected when geocoding. The resulting coordinate data were visually inspected in the CSV file and in a map interface for quality control. Most libraries were geocoded to the highest-level possible (zip code); some were geocoded to city-level accuracy; and a small number were geocoded to the country-level. Once coordinate data were assigned to each library, the distance of each of those libraries from the CU Boulder Library were calculated using Python. The Python library GeoPy contains a function for calculating geodesic distance. The geodesic distance calculation method is preferred for data that is global in scale (as opposed to normal planar calculations, which do not take into effect the Earth's curvature). These distance calculations were inputted into a final CSV file that contained coordinate data and distance from CU Boulder for each library in the data. Finally, the CSV file containing distance and coordinate information was merged with the file containing the OCLC item location data to create a master table with which further analyses were conducted.

Additional data used in the analysis included bibliographic data attributed to each item retrieved from the bibliographic records found in the University of Colorado Boulder's (UCB) integrated library system. The additional data fields retrieved included publication language and call number. Call numbers were further analyzed by attributing the Library of Congress (LC) call numbers to the applicable LC classification subclass using the LC classification outline. ${ }^{36}$ Item, bibliographic, and LC classification subclass data was compiled in Excel and analyzed through pivot tables.

\section{Results}

The dataset analyzed contained 16,481 items, of which 244 were unique to $\mathrm{CU}$ Boulder Libraries, and 16,237 were held at UCB and at least one other library. A total of 8,641 items (52 percent) were held at forty-nine or fewer libraries. The remaining 7,838 items (48 percent) were held at fifty or more libraries. 
Figure 1 plots the count of items held at institution by the number of holdings from items unique to UCB to items held at forty-nine institutions. As the figure illustrates, the number of items held at between one and nine libraries steadily increases, peaking at nine. After nine libraries, the number of items held decreases. Because of this spike, and of similar analysis that used ten or less holdings, for the analysis of unique, rare, and scarce items, the authors focused on items held at nine or fewer libraries, including UCB.

\section{Top Twenty-Five Institutions With Two to Nine Holdings that Share Items with UBC}

Some of the largest, most prominent libraries in the United States represented the top libraries with shared items between two to nine holdings, including the Library of Congress, Harvard, and the University of California Berkeley. The closest of these locations was the University of Minnesota, Minneapolis, approximately seven hundred miles away. Of the twenty-five libraries, six were outside North America, including Japan, Germany, Spain, South Africa, and Australia (see table 1).

Only five libraries shared six or more items uniquely with UCB. The top two locations in this group were international, meaning that of the fifty-two items in this set, UCB's copy was the only copy held in the United States (see table 2).

\section{Characteristics of Items Held at Nine or Fewer Libraries}

In total, 905 items (36 percent) were in English, with the remaining 63.5 percent in a range of other languages. Japanese, Spanish, and Persian were the next most prevalent languages. Table 3 also shows the percentage of items within the set that were unique items only found at UBC. Twenty-one percent of the Spanish language materials are unique, while thirteen percent of both the Persian and Chinese language materials are unique. Nine percent of the English language materials are unique.

Four of the top five LC classifications describe subject areas relevant to area studies research, with Indo-Iranian languages and literatures as the top LC classification. The second most prevalent LC classification was the theory and practice of education (see table 4).

\section{Nearest Copies in the Full Dataset}

\section{Within a 200-mile Radius}

In comparing items also held by other institutions, 5,978 items (37 percent) were held at an institution within a 200 mile radius. The University of Denver shared the most overlap (1,000), followed by the Auraria Library, which serves a sister campus, the University of Colorado, Denver (944), and Regis University (898), also located in Denver (see figure 2).

\section{Within a 550-mile Radius}

A total of 10,165 of the items (63 percent) were held at institutions within a 550-mile radius. Brigham Young University in Provo, Utah was the nearest location in this radius with the most overlap $(1,136)$, followed by the University of Kansas $(1,108)$, and again, the University of Denver $(1,000)$ (see fiure 2).

\section{Outside North America}

Nearly all items (98 percent) were held at institutions in North America, including Canada and Mexico. Brigham Young University, the University of Kansas, and the University of Denver continued to be the top three institutions across North America with shared holdings. However, 279 items were held by institutions outside of North America in addition to being held at UCB. These included institutions in Europe, Australia, and Japan (see figure 3). 


\section{Discussion}

If holdings and locations are used as a measure of "specialness" or "uniqueness," the majority of items UBC added to the general collection as gifts were not unique, nor were they particularly rare or geographically scarce. Abandoning a gifts-in-kind program altogether based on these results would not be prudent, however, as some items were unique or geographically scarce. For example, some items were the only copy found in the United States or in North America or were one of nine or fewer holdings worldwide. As librarians have long recognized, treasure can be found hidden among the "trash," but the process of evaluation may warrant additional data to better assess value. Using WorldCat holdings and geospatial data may help libraries like UCB to better evaluate potential donations at the time of inquiry from the donor, rather than after acceptance and processing of gift-in-kind items.

\section{OCLC Holdings and the WorldCat Search API}

Leveraging data science techniques streamlined several phases of this research. Automating the data collection process via the WorldCat Search API opened paths of inquiry that were previously unavailable. Collecting information about the nearest copies of more than sixteen thousand books manually is almost impossible. Running a script to obtain this data-even when slowing the speed of the script down to maintain a "polite" request rate-took a few hours to complete. Whereas libraries have long relied on OCLC's catalog and metadata services, few have leveraged the rich data content of what is perhaps the world's most comprehensive library catalog. By taking advantage of the WorldCat Search API, the authors added the new data points of uniqueness and distance of copies to the decision matrix for assessing gift items-improving upon the standard assessment of "do we have it?"

An added benefit of the data science approach is the ability to reproduce this type of analysis with ease and on a variety of scales. For a collection of gift items totaling more Boulder Libraries.
Table 1. The top 25 institutions with whom the University of Colorado Boulder Libraries shares items with between 1-9 holdings.

\begin{tabular}{|llc}
\hline Institution & Country & $\begin{array}{c}\text { Total Shared Items, } \\
\text { Holdings 1-9 }\end{array}$ \\
\hline Library of Congress & USA & 464 \\
\hline Harvard University & USA & 372 \\
\hline UC Berkeley Libraries & USA & 370 \\
\hline University of Illinois at Urbana Champaign & USA & 350 \\
\hline National Diet Library & Japan & 310 \\
\hline University of Washington Libraries & USA & 298 \\
\hline University of Chicago Library & USA & 275 \\
\hline University of Minnesota, Minneapolis & USA & 264 \\
\hline Columbia University in the City of New York & USA & 261 \\
\hline HCL Technical Services & USA & 182 \\
\hline University of Erlangen-Nuremberg & Germany & 175 \\
\hline University of California, NRLF & USA & 175 \\
\hline HathiTrust Digital Library & USA & 169 \\
\hline Yale University Library & USA & 161 \\
\hline University of Sydney Library & Australia & 157 \\
\hline University of Kentucky Libraries & USA & 155 \\
\hline Biblioteca Nacional de España & Spain & 144 \\
\hline Unisa: Muckleneuk Campus & South Africa & 141 \\
\hline University of Texas Libraries & USA & 135 \\
\hline Princeton University Library & USA & 124 \\
\hline University of Toronto Robarts Library & Canada & 123 \\
\hline International Research Center for Japanese Studies & Japan & 116 \\
\hline University of British Columbia Library & Canada & 107 \\
\hline University of California, Los Angeles & USA & \\
\hline Stanford University Libraries & USA & 107 \\
\hline & & 29 \\
\hline
\end{tabular}

Table 2. Libraries sharing the most unique items with the University of Colorado

\section{Institution and Location}

Count of Shared Items

Biblioteca Nacional de España; Madrid, Spain $\quad 31$

National Diet Library; Tokyo, Japan

Library of Congress; Washington, DC, United States

11

Alibris; Emeryville, California, United States

University of Texas Libraries; Austin, Texas, United States

than a few dozen books, querying the WorldCat Search API for the items' library locations amounts to a significant time-saving. For small collections (i.e., fewer than several hundred), adding these metrics to the decision process takes seconds or minutes to complete. All that is needed is a list of the items' OCLC numbers or ISBNs. Using program 
Table 3. Top 10 Languages by Item Count.

\begin{tabular}{lcccc}
\hline Language & Item count & $\begin{array}{c}\text { Percentage of hold- } \\
\text { ings 1-9 }\end{array}$ & $\begin{array}{c}\text { Unique items (holdings only at } \\
\text { CU Boulder) }\end{array}$ & $\begin{array}{c}\text { Percentage of unique items by } \\
\text { language }\end{array}$ \\
\hline English & 905 & $36 \%$ & 83 & $9 \%$ \\
\hline Japanese & 395 & $16 \%$ & 10 & $3 \%$ \\
\hline Spanish & 311 & $13 \%$ & 64 & $21 \%$ \\
\hline Persian & 248 & $10 \%$ & 33 & $13 \%$ \\
\hline Chinese & 178 & $7 \%$ & 23 & $13 \%$ \\
\hline Hindi & 73 & $3 \%$ & 4 & $5 \%$ \\
\hline Urdu & 72 & $3 \%$ & 4 & $6 \%$ \\
\hline Portuguese & 64 & $3 \%$ & 3 & $5 \%$ \\
\hline Korean & 58 & $2 \%$ & 4 & $7 \%$ \\
\hline German & 40 & $2 \%$ & 4 & $10 \%$ \\
\hline
\end{tabular}

Table 4. Top 10 LC classifications for items held at 1-9 institutions.

\begin{tabular}{llc}
\hline LC Classification & Classification Description & Item Count \\
\hline PK & Indo-Iranian languages and literatures & 300 \\
\hline LB & Theory and practice of education & 285 \\
\hline PQ & $\begin{array}{l}\text { French literature - Italian literature - Spanish } \\
\text { literature - Portuguese literature }\end{array}$ & 259 \\
\hline PL & $\begin{array}{l}\text { Languages and literatures of Eastern Asia, Africa, } \\
\text { Oceania }\end{array}$ & 186 \\
\hline DS & Asia & 97 \\
\hline PS & American literature & 82 \\
\hline PN & Literature (general) & 62 \\
\hline N & Visual arts & 54 \\
F & All Americas & 47 \\
\hline QA & Mathematics & 46 \\
\hline
\end{tabular}

code instead of proprietary software, documentation of the methodology is essentially built into the scripts. Beyond an OCLC subscription and basic programming knowledge, those wishing to repeat these methods need only to install Python and the related code libraries - all of which are free and open source. Use of OCLC's suite of APIs is ripe with potential for collection analyses, and librarians that regularly conduct collection assessments should explore the multitude of data and uses available to them.

\section{Geospatial Data Techniques for Collections Analysis}

As previously noted, evaluating OCLC holdings to analyze collections and to make evaluation decisions for potential donations is not uncommon. What many previous methods have not used in the same manner as this research is the inclusion of geospatial techniques to provide additional data and context to the process. The GIST tool offers information about the number of holdings within specific groupings of libraries, for example, the number of libraries in the state of New York within a specific interlibrary loan network. For libraries in geographically dispersed regions, such as the West, the Great Plains, or the Rocky Mountain region, physical distance may be a consideration, knowing not only the location of the nearest copy of an item, but also the distance to that next copy. While interlibrary loan is a consideration when reviewing data for individual items, geospatial analysis may be important in considering collections as a whole. The geospatial techniques used in this research to provide more data for gift-in-kind collection analysis could also be used to in collection analysis and evaluation for purchased materials.

For example, UCB houses a large East Asian studies research collection. The next closest comparable collections are at Brigham Young University and the University of Kansas, both more than five hundred miles from Boulder. Is there a maximum distance to the next closest copy that may be considered when building a collection, acquiring new material, or considering donations? Is over five hundred miles acceptable, or should a library consider adding items when they are not found within a five hundred-mile radius? What is an appropriate distance to consider, particularly for libraries located in geographically dispersed regions? Data-driven geospatial techniques provide new methods of analysis and techniques to consider, particularly for large collections and datasets that require efficient methods of analysis. 


\section{Retroactive Analysis}

What can a retroactive analysis of a set of donated materials reveal about the future of gifts-in-kind? The shared characteristics of items held at nine or fewer libraries, including the items unique to UCB, may help illustrate why these are rare. Many of these items held at nine or fewer institutions are materials in languages other than English, and some are also found in LC classifications relevant to Area Studies researchers. Area Studies collections, like Special Collections, have qualities of distinctiveness. ${ }^{37}$ Language and subject area, particularly emphasizing the areas of international studies relevant to a library's students, faculty, and researchers, could become significant factors in evaluating potential gifts-in-kind in the future. Furthermore, because historic means of acquiring Area Studies and international materials are no longer feasible for many libraries, with federal funding grants supporting materials to teach foreign languages in higher education increasingly limited and international acquisitions trips financially unviable, donated materials may offer an alternative means to obtain difficult to acquire materials. ${ }^{38}$

Since the acceptance of items evaluated in this research (2006-2016), the manner in which UCB staff communicate with potential donors has changed, and includes intial questions on describing a donation, and whether a donation includes items in languages other than English. These types of questions have enabled prioritization for review and processing of donations that have more potential of being unique or special, and has resulted in recently accepted gifts of Tibetan manuscripts and noir and crime fiction novels from Japan. Additionally, implementing the automated techniques for compiling OCLC holdings and geospatial data is currently being explored to incorporate into student employee workflows, as they do the bulk of data collection for the evaluation process.

What this research did not analyze, but would be beneficial for future research, is to more closely examine the characteristics of items that are both commonly held across many institutions, plus items that are prevalent within the geographic region. An analysis of LC classifications or other characteristics may reveal the types of items or subject areas that are the least desirable as gifts-in-kind. Better understanding

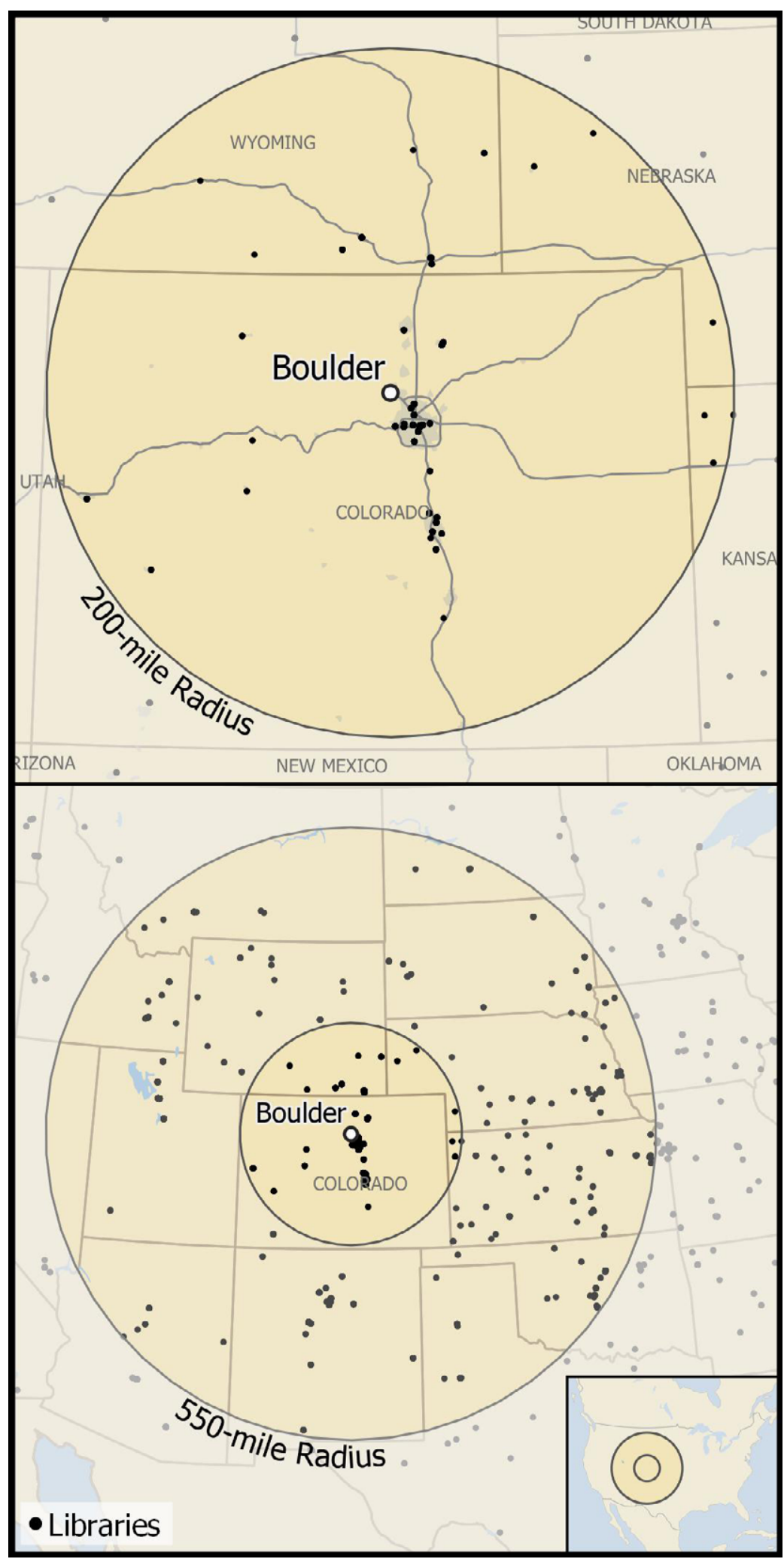

Figure 2. Map depicting libraries that held the nearest copies of any of the donated items within 200 -and 550 -mile radii. 


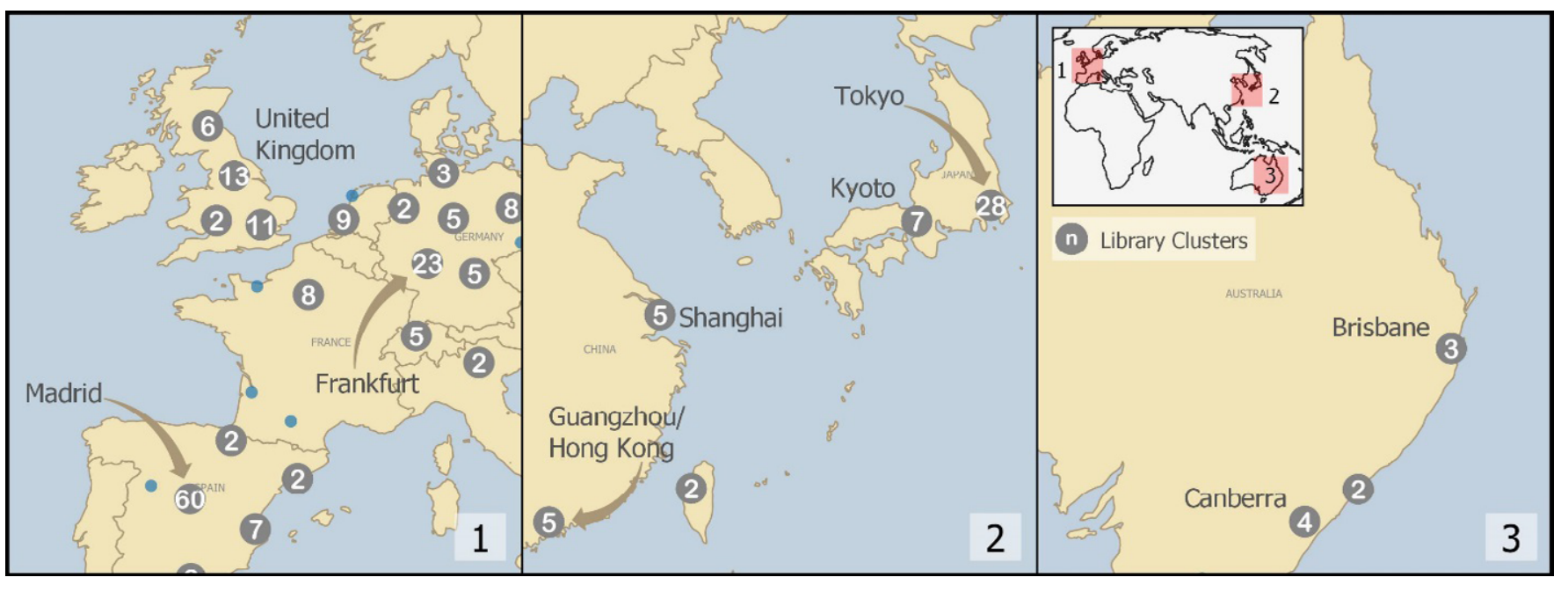

Figure 3. Map depicting clusters of libraries in areas beyond North America where nearest copies of items most often occurred. 1. Western Europe; 2. East Asia; 3. Australia.

of commonly held or regionally prevalent items may further help libraries to limit the amount of upfront work needed, and perhaps minimize the need to compile additional data on OCLC holdings or geographic scarcity for this subset of materials.

Finally, future research on gifts-in-kind evaluation would benefit from applying evaluation methods that are emerging in collection development and assessment, focused on evaluating materials for inclusion of traditionally underrepresented and marginalized communities. This may involve analysis of subject headings, author bibliographic information, plus considerations for small and independent presses, or non-traditional or author-published works. Are there additional ways techniques developed in this research using the WorldCat Search API could provide data that can highlight works from traditionally underrepresented communities?

\section{Limitations}

Although the methods and resulting analyses presented were highly effective and beneficial to the authors' giftin-kind assessment efforts, they acknowledge that limitations exist. First, using the graphic distance of other item copies was important to UCB but may be irrelevant to others, depending on location. UCB serves a region with a relatively low-density of large academic or research libraries. Beyond the greater Denver area, distances between institutions in the Rocky Mountain Region are highunderscoring the importance that UCB retains local copies of relatively unique items. For libraries in regions encompassing many research libraries (e.g., the Northeast, the West Coast), retaining local copies may not be important if several nearby libraries hold the items. Assessing distance and uniqueness, however, could still be relevant to libraries in these high-density areas as points of decision for adding items to the collection. Although others may easily replicate this study's assessment approach, the results produced are only relevant locally. Future studies could further develop the techniques presented to compare multiple institutions or regional borrowing networks to draw broader conclusions regarding collection uniqueness and geographic scarcity.

Another limitation of this study is its reliance on OCLC's systems and assumptions about its data quality. In addressing the study's repeatability, the authors assert that most libraries have access to OCLC services. Whereas this may be true for large US research libraries, this is not a fair assumption for libraries without an OCLC subscription such as small, specialized, or international libraries. The WorldCat Search API is inaccessible to such libraries and their catalog records may not be a part of the WorldCat database. The authors acknowledge this inherent limitation and partiality toward libraries in the US and broader western world. Additionally, the authors recognize that this research relies on the quality of OCLC's data. It should be noted that multiple OCLC numbers could be assigned to a unique item, which may affect the results of this study. More research inquiring about how frequently unique items are assigned multiple OCLC numbers would be useful. Future researchers looking to mitigate this factor may choose to query the WorldCat Search API with ISBNs, and not OCLC numbers. Older, unique, and rare materials, however, may lack an OCLC number, an ISBN, or both. Thus, some materials without any identifies could not be analyzed using the WorldCat Search API. 


\section{Conclusion}

Although the results of this study were localized, the methods developed could be easily replicated by any library seeking to develop data-driven decision-making in the gift-in-kind process with high efficiency and objectivity. Retroactive analysis can offer insight into improvements on future evaluation criteria for potential donations, while the methods themselves both using the WorldCat Search API and geospatial analysis techniques could be applied to large offerings, if OCLC numbers or ISBNs are collected. Researchers could replicate these methods on datasets beyond donated materials, offering new ways of analyzing collections and similarly developing new criteria for acquisitions and collection development policies and scope in the future. Sifting through "trash" versus "treasure" does not have to be a highly subjective, labor-intensive process. The methods applied in this research can be used to build datadriven decision-making into the gift-in-kind process.

\section{References and Notes}

1. John Ballestro and Philip C. Howze, "When a Gift Is Not a Gift: Collection Assessment Using Cost-Benefit Analysis," Collection Management 30, no. 3 (2006): 49-66, https://doi .org/10.1300/J105v30n03_05.

2. "Cleveland PL Maintains Largest Chess Collection," Library Journal 113, no. 3 (1988): 118; "British Literature Gift to Alfred Univ," Library Journal 107, no. 4 (1982): 394.

3. Joseph A. Williams, "Is Trash a Library's Treasure? A Study of Gifts-in-Kind Practices and Policies among New York State Libraries," Library Collections, Acquisitions \& Technical Services 38, no. 1-2 (2014): 1-9.

4. "Gifts Policy," University Libraries, last updated August, 24, 2016, accessed February 25, 2019, https://www.colo rado.edu/libraries/about/policies/gifts-policy.

5. Columbia University Libraries, "Gifts in Kind Policy," accessed August 29, 2018, https://library.columbia.edu /about/policies/gifts-policy.html.

6. Hesburgh Libraries, "Hesburgh Libraries Gift Policy," accessed August 29, 2018, https://library.nd.edu/hesburgh -libraries-gift-policy.

7. Janet Bishop, Patricia A. Smith, and Chris Sugnet, "Refocusing a Gift Program in an Academic Library," Library Collections, Acquisitions, \& Technical Services 34, no. 4 (2010): 115-22.

8. Bishop, Smith, and Sugnet, 120.

9. Williams, "Is Trash a Library's Treasure?"

10. Steve Carrico and Michael A. Arthur, "Being Earnest With Collections--Materials Gifts in Libraries: Same Old, Same Old? Maybe Not," Against the Grain 28, no. 1 (2016), https://doi.org/10.7771/2380-176X.7294.

11. Donna Canevari de Paredes, "Gifts-in-Kind in the Academic Library: The University of Saskatchewan Experience," Library Collections, Acquisitions, \& Technical Services 30, no. 1-2 (2006): 55-68, https://doi.org/10.1080 /14649055.2006.10766106.

12. Canevari de Paredes, "Gifts in Kind in the Academic Library," 55-56.

13. Sheila O'Hare and Andrew Smith, "Gifts Nobody Wants: The State of the Art in Dealing with Unwanted Donations,"
Kansas Library Association College and University Libraries Section Proceedings 1, no. 1 ( 2011): 66-86, https://doi .org/10.4148/culs.vli0.1363.

14. James Burgett, "Unpacking a Donor's Library: A Gifts Librarian's Nod to Walter Benjamin," The Acquisitions Librarian 11, no. 22 (1999): 8, https://doi.org/10.1300/J101 v1ln22_02.

15. Catherine Denning, "Introduction," The Acquisitions Librarian 11, no. 22 (1999): 2, https://www.tandfonline .com/doi/abs/10.1300/J101v11n22_01.

16. Canevari de Paredes, "Gifts-in-Kind in the Academic Library."

17. William Joseph Thomas and Daniel Shouse, "This Is Not a Dumpsite: The Problem of Evaluating Gift Books," Library Collections, Acquisitions, \& Technical Services 38, no. 3-4 (2014): 63-69.

18. Steve Johnson, "Automating Gifts and Exchanges: A Review of Current Trends," The Acquisitions Librarian 11, no. 22 (1999): 59-73, https://doi.org/10.1300/J101v11n22_06.

19. Michelle Emanuel, "Managing In-Kind Gifts with Getting It Started Toolkit's Gifts and Deselection Manager," Library Collections, Acquisitions \& Technical Services 38, no. 1-2 (2014): 21-27.

20. Getting It System Toolkit, "GIST Gift and Deselection Manager" (Education, 08:54:35 UTC), https://www.slide share.net/gettingitsystemtoolkit/gist-gift-and-deselection -manager.

21. Michael Brewer, "Identifying Holdings Unique to Your Library's Collections Using WorldCat," Slavic \& East European Information Resources 7, no. 4 (2007): 115-21, https://doi.org/10.1300/J167v07n04_08.

22. Paul Genoni and Janette Wright, "Australia's National Research Collection: Overlap, Uniqueness, and Distribution," Australian Academic \& Research Libraries 42, no. 3 (2011): 162-78.

23. American Library Association, "Guidelines on the Selection and Transfer of Materials from General Collections to Special Collections: Approved by the ACRL Board of Directors, July 2008," College \& Research Libraries News 
69, no. 10 (2008): 630-37.

24. Michael Barnes, Robert G. Kelly, and Maureen Kerwin, "Lost Gems: Identifying Rare and Unusual Monographs in a University's Circulating Collection," Library Collections, Acquisitions, \& Technical Services 34, no. 2-3 (2010): 57-65, https://doi.org/10.1080/14649055.2010.10766261.

25. Brewer, "Identifying Holdings Unique to Your Library's Collections Using WorldCat."

26. A full list of OCLC's API offerings along with documentation is available at https://platform.worldcat.org/api-explorer lapis.

27. See https://www.oclc.org/developer/develop/web-services /worldcat-search-api.en.html.

28. Leonard Richardson and Sam Ruby, "Preface," in RESTful Web Services, by Leonard Richardson and Sam Ruby (Beijing: OReilly, 2007), https:/www.safaribooksonline.com /library/view/restful-web-services/9780596529260/pr05.html.

29. The base URL is http://www.worldcat.org/webservices /catalog.

30. See OCLC Developers Network for more information: https://www.oclc.org/developer/home.en.html.

31. See https://www.oclc.org/developer/develop/worldshare -platform/terms-and-conditions.en.html.
32. All Python scripts used in this study are available at https:// github.com/outpw/WorldCatLocations.

33. WorldCat Search API does not return street addresses, only city, state, and zip code.

34. Documentation available at https://developer.mapquest.com /documentation/geocoding-api/.

35. See http://www.worldcat.org/oclc/906871620.

36. "Library of Congress Classification Outline," Library of Congress Classification Outline, accessed October 5, 2018, https://www.loc.gov/catdir/cpso/lcco/.

37. Lisa R. Carter and Beth M. Whittaker, "Area Studies and Special Collections: Shared Challenges, Shared Strength," portal: Libraries of the Academy 15, no. 2 (2015): 353-73.

38. Funding for the National Resource Center Program, intended to provide universities with grants to establish strengthen, and operate language and areas studies centers was $\$ 22,743,107$ in 2014 , and is projected to remain at the same funding level into 2021; "National Resource Centers Program Awards," National Resource Centers, accessed February 22, 2019, https://www2.ed.gov/programs/iegpsnrc /awards.html. 